\title{
O feminismo no plural: para pensar a diversidade constitutiva das mulheres
}

Féminisme(s) Penser la plura lité. Cahiers du Genre, n. 39.

FOUGEYROLLAS-SCHWEBEL, Dominique; LÉPINARD, Éléonore; VARIKAS, Eleni (Coordonné).

Paris: L'Harmattan, 2005. 264 p.

A revista Cadernos de Gênero é uma publicação que tem a colaboração do Centro Nacional da Pesquisa Científica/CNRS/França; do Serviço de Direitos das Mulheres e da Igualda de; do Centro Nacional do Livro e do Laboratório Gênero, Trabalho, Mobilidades/IRESCO/CNRS Universida des Paris 10 e Paris 8 - ex-GERS.

Esse número se propõe a trazer estudos sobre a diversidade constitutiva das mulheres, a partir da problematização de uma de suas dimensões, que se refere à imbricação das dominações sexistas e racistas. Nesse sentido, o Caderno traz a ná lises teóric as e polític as a partir de experiências do black feminism americano, que se coloca no campo central dos debates do feminismo a meric a no, nos últimos tempos, a partir de provocações das feministas a fro-americ anas e de mulheres de grupos minoritários.

Esse trabalho compreende que a luta pela plura lida de humana não se limita à compreensã o da existência da bica tegorização hierárquica de sexo, mas deve tratar da construção homogeneizadora e da categoria normativa das mulheres, para exporas diversas experiências das mulheres, as diferentes formas de a ssujeita mento das mesmas, a diversidade das condições de vida e das relações de poder das mulheres que as faz alcançara liberdade de forma desigual.

o primeiro texto é de Dominique Foug eyrollas-Sc hwebel, socióloga, pesquisa dora do CNRS/França, e membro do comitê de redação da revista Cadernos de Gênero. Dominique analisa as divisões no interior do feminismo francês a partir das escolhas das estra tégias políticas. Traz a centralidade das referências marxistas nos a nos 1970 e considera essa determinante para promover rupturas com as práticas de dominação.
Nancy Fraser é professora de Filosofia no doutorado da Nova Escola para Pesquisa Social de Nova York. No seu texto aprofunda e traz esclarecimentos sobre a questão da diferença, categoria tratada pelo movimento feminista desde os anos 1960, que hoje enfrenta impasses e para a qual Fraser indica algumas possibilidades. Se no início tratava-se de trabalhar com a oposição "igualda de-diferença", depois com as "diferenças entre mulheres", agora se reflete sobre "diferenças cruza das múltiplas", para incorporar o debate sobre gênero, raça, etnia, classe e sexualidade. Fraser afirma que, no terreno mais a mplo da socieda de civil, múltiplos eixos das lutas de gênero se expõem com a intersec ção dos movimentos socia is e a nalisa os limites das correntes anti-essencialistas e multic ultura listas que ora se defrontam nos Estados Unidose que podem colocar "num mesmo saco toda identidade". Propõe no seu texto relacionar a busca de identidades e de afirmação de diferençasa partir da exigência de justiça social, de alargamento da democracia, da igualdade social. Fraser traz ainda reflexões sobre a significação do temo democracia radical, que passa pordesafiosatua is, quando os movimentos feministas se voltam basicamente para desenvolver uma política cultural de reconhec imento. Tanto o anti-essencia lismo como o multic ultura lismo se volta $\mathrm{m}$ ma is priorita ria mente para os efeitos nefastos do nã o-rec onhec imento cultural e relevam a importância da desigual divisão político-econômica. Para Fraser, o princípio da igualdade e justiça social deve ser trata do pelos movimentos na mesma medida que o reconhecimento cultural.

Segue-se então o texto de Kimberlé W. Crenshaw, considerado clássico. Kimberlé é professora de Direito na UCLA e na Universidade Columbia. Seu trabalho trata das violências conjuga is nas comunidades a fro-a mericanas e sugere a criação de instrumentos teóricos para pensar essa realidade. Apresenta o conceito de intersecciona lida de, pa ra a na lisa ra intersec ção entre as dominações de sexo e de raça. Para Kimberlé, as relações de dominação encontra das nas análises das categorias de sexo e de raça devem serpensadastambém como estruturas de dominação. Destaca o cuidado e a a tenção para os estudos não se fecharem nessa interp retação (de sexo e raça), mas também apostarem nas 
reflexões sobre a pluralidade e a diversidade constitutiva das mulheres, que podem articular relações so cia is de c a ráter e de origens diversas, como de classe e sexo, cujos trabalhosna França são exemplares. Kimberlé trata, num primeiro momento, da intersec ciona lida de estrutural pa ra explicar a posição das mulheres de cor diante das suas experiências concretas de violência conjugal. A autora faz um estudo em comunidades de mulheres refugiadas em Los Angeles e identific a um quadro de subordinação em que elas vivem. A maioria é desempregada, ou com subemprego, são pobres, são as responsá veis pelas atividades familiares, e não possuem competências profissionais. Estudar a relação entre raça, gênero e classe é fundamental para compreender as suas intersecções. No segundo momento, Kimberlé trata da interseccionalidade política, em que a na lisa a margina liza ção da questão da violência contra as mulheres de cornas polític as feministas e anti-racistas. Parte da reflexão de que a mulher de cornão vive as dimensões de sexo e de raça como os homens negros e as mulheres brancas. Para isso, serve-se do conceito de raça e de patriarca do para a na lisara dupla margina lização das mulheres de cor.

Elsa Dorlin é mestre de conferências em Filosofia na Universidade Paris I - PantheonSorbonne. Recuperando a historicidade das mulheres negras nos Estados Unidos, Dorlin problematiza as colisões entre "sexo" e "raça" e feminismo e racismo. Lembra ela que durante a luta pelo sufrágio feminino, quando as mobiliza ções feministas a meric a nas a ponta va $m$ para uma única campanha pelo sufrágio, as mulheres brancas reagiram defendendo a sua cond ição de mulher. A dimensão de dominação parecia a tra vessaressa relação e foi decisiva na criação de uma fronteira entre mulheresbrancas e negras, maior a té que entre homense mulheres brancas. A prioridade da luta das mulheres brancas obscureceu e a nulou outros sujeitos do feminismo - a mulher negra. A partir dessa experiência, Dorlin passa a problematizar a dificuldade do feminismo de tratar, nos tempos atuais, a questão do racismo e dos direitos da mulher negra. Assim é que nos Estados Unidos o surg imento do black feminism se constitui numa verdadeira revolução. Questiona o sujeito mesmo do feminismo - as mulheres - e a sua categorização homogênea, mas o debate está se abrindo para a teoria anglo-saxônica. A produção de um conceito de subjetivação parece ser um caminho para compreender os processos pelos qua is os indivíduos forjam uma identidade política por onde eles lutam e se a fima m como sujeitos de sua própria libertação. A partir dessa a nálise, o sujeito do feminismo está em constante produção e não se aprisiona em nenhuma definição norma tiva. Esc a varas formas de dominação sobre as mulherese as suas formas de luta e de resistência para superar essa dominação é invenção de uma outra linguagem política.

O texto de Eleonore Lépinard (doutora em Sociologia/Canadá) avalia que a categoria da diferença é central dentro do projeto feminista e deve ser enfrentada na sua dimensão teórica e política. Lépinard analisa a impotência da França de pensar a configuração particular do sexismo e do racismo que se abate sobre as mulheres imigrantes ou francesas, frutos da escravidão e da colonização. O feminismo francês não tem construído instrumentos para compreender a divisão intema entre as mulheres.

Para as francesas, a pesarde reconhecerem a existência de análises rigorosas sobre os mecanismos de categorização de sexo e de raça, o dilema de desenvolverna França uma política anti-racista feminista a inda está presente.

Historicamente, no seio do feminismo europeu trabalhou-se o sexo a partir de uma clivagem de classe, que resultou em inúmeros estudos sobre o trabalho e a família, a transversalidade das relações sociais de sexo e de classe, a relação entre capitalismo e patriarcado. O desafio ora colocado para as feministas européias refere-se à nec essidade de compreender "os interesses divergentes, senão contraditórios, entre mulheres diplomadas, mulheres não qualificadas, mulheres do Norte, mulheres do Sul", ou seja, de "compreender segundo quais modalidades certas mulheres participam dessas relações de dominação" (p. 8).

O feminismo é então trazido para ser refletid o como um posic ionamento, um modo de agir político, e nesse sentido deve ser pensado no plural, para garantir a incorporação das diferenças nas relações de poder, vivenciadas entre mulheres que guardam interesses diversos e a té contraditórios.

Sonia Dayan-Herzbrun faz reflexões a partir de seu locus de observação, "le Proche-Orient", e das práticas de resistência dos palestinos dos teritónios oc upa dos, como os campos do Líbano. Seu trabalho leva em conta os investimentos polític os do privado, suas práticas de resistência e coloca-se na escuta do que falam e fazem os palestinos e como são categorizados como dominados. 
A questão do feminismo perpassa todos os textos em uma perspectiva de tratá-lo como um projeto político, que não pressupõe uma via única, mas a reunião de solidariedades a se construir.

A revista Cadernos de Gênero traz ainda três contribuições de a uto res so bre temas diversos: o texto que trata dastransformações das relações socia is de sexo e de sua snova sproblematiza ções pelas ciências sociais; o texto a respeito de uma pesquisa realizada na Espanha sobre abuso sexual em três luga res de trabalho e os diferentes comportamentos das mulheres diante das práticas masculinas que poderiam ser compreendidas como assédio sexual; e o texto em torno de uma outra pesquisa ta mbém realizada na Espanha sobre as ma is variadas dimensões do trabalho não remunera do na rede familiar e assumidos pelas mulheres.

No final nos brinda com algumas resenhas de livros como Identidade nacional e procriação no Brasil: sexo, classe, raça e esterilização feminina, de Valeria Ribeiro Corossacz; e Cultura hip-hop, jovens das cidades e políticas públicas, de Sylvia Faure e Marie-Carmen Garcia, dentre outros trabalhos resenhados.

Gema Galgani Silveira Leite Esmeraldo Universidade Federal do Ceará 